\title{
Histoacryl tissue adhesive in some types of retinal detachment surgery
}

\author{
LUCIAN REGENBOGEN, AMALIA ROMANO, MOSHE ZUCKERMAN, AND \\ RICHARD STEIN \\ Department of Ophthalmology, The Chaim Sheba Medical Center, Tel Hashomer, Tel-Aviv University \\ Medical School, Israel
}

Cyanoacrylate has been used in general surgery for several years for patching vascular defects and closing skin incisions (Natan, 1960; Healey, 1965). The compound most often used is methyl 2cyanoacrylate because it is biodegradable and rapidly produces strong adhesions, but it can cause tissue inflammation and necrosis.

The availability of several new cyanoacrylates has prompted a number of studies reporting the merits, disadvantages, and possible applications of these agents in eye surgery. Since the first reports on the use of tissue adhesives (Straatsma, Allen, Hale, and Gomez, 1963; Ellis and Levine, 1963), several types of glue have been tried in experimental ophthalmic surgical procedures (Seelenfreund, Refojo, and Schepens, 1970; Calabria, Pruett, Refojo, and Schepens, 1970; Long, Mittli, and Chuanico, 1970).

The use of cyanoacrylate adhesive in rabbits to close perforation after drainage of subretinal fluid or at sites over pars plana ciliaris after intravitreal injection has been reported by Seelenfreund and others (1970). Calabria, Pruett, and Refojo (197I) used this adhesive in sutureless experimental buckling techniques.

Implants composed of homologous sclera and cyanoacrylate were investigated by Vygantas and Kanter (1974) in scleral buckling procedures performed on rabbits' eyes. Implants and explants were produced by glueing together a few strips of sclera after application of isobutyl 2-cyanoacrylate on one side of each sclera strip.

Pruett (1972) described the cyanoacrylate properties when used for sealing perforations, reinforcing scleral laceration, or anchoring solid silicone in retinal surgery.

The purpose of this paper is to report the clinical results obtained in retinal detachment surgery by different types of scleral buckling in cases in which histoacryl-blue adhesive tissue and preserved

Address for reprints: Lucian Regenbogen, MD, Department of Ophthalmology, The Chaim Sheba Medical Center, Tel-Hashomer, Israel scleral graft were used to support staphylomatous areas or to create indentation effect.

\section{Materials and methods}

The glue used was histoacryl adhesive tissue (N-Butyl Ester of A-Cyanoacrylate).* The glue is blue in colour due to the addition of $O \cdot I$ per cent-I-hydroxy-4-(Ptaluidine)-antrachinon. The adhesive must be spread as thinly as possible and after accurate adaptation the tissue surfaces should be pressed together for one minute to ensure adequate adhesion. The polymerization time is very short-only Io seconds; therefore, caution must be exercised to adapt the tissue. The layers of adhesive introduced into the tissues and the stain are absorbed completely within a short period of time (Ellis and Levine, 1963; Seelenfreund and others, 1970; Calabria and others, 1970; Long and others, 1970). Except for the sclera, contact between the adhesive and other eye tissues and instruments should be carefully avoided.

The scleral grafts were obtained from the eyes of human cadaver and preserved using the method of Paufique and Hervouet (1962). A combination of histoacryl and preserved sclera was used in full-thickness scleral buckling with silicone sponge, circling buckling with intrascleral trapdoor implant, and partial buckling with scleral pocket. Postoperatively, antibiotic and corticosteroid drops were applied locally for io days. Slit-lamp and fundus examinations were performed weekly during the first four weeks, and monthly for six months thereafter.

\section{Case reports}

CASE I

A 58-year-old man was admitted for almost total bullous retinal detachment with a horseshoe tear at I o'clock meridian in his left high myopic eye. A circling buckling with scleral trapdoor and silicone implant in the upper temporal quadrant was planned. After exposure of the sclera, a bulging staphyloma of temporalhalf of the eyeball was encountered (Fig. I). The thinness of the sclera made dissection impossible and anchorage of silicone sponge explant could not be

*Manufactured by S. Braun Melsungen, W. Germany 

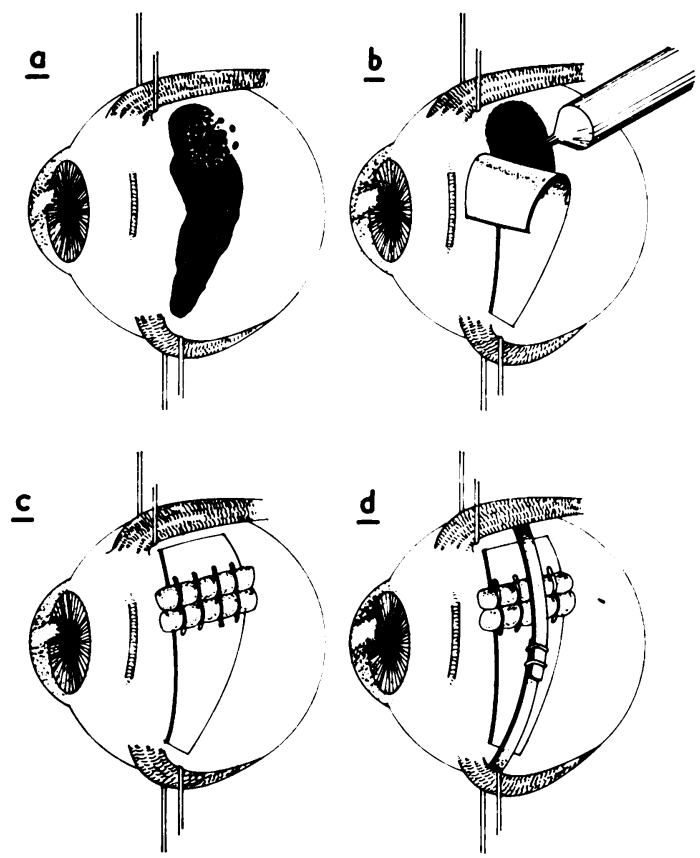

FIG. I (a) Slight non-penetrating diathermy placed on surface of staphylomatus area around tear. (b) Glueing of preserved scleral patch with histoacryl. (c) Glued-on patch with sutures holding two silicone sponge elements.

(d) Closure of encircling band on scleral graft

carried out without danger of perforating the eye. Therefore, a preserved human scleral patch was glued with the aid of histoacryl to the staphylomatous area, preceded by light diathermy of the tear area. The scleral patch was pressed to its bed with a finger for one minute. The adhesion between the original sclera and the patch proved strong enough to keep the anchoring suture in place for the insertion of two radial silicone sponge explants of $5 \mathrm{~mm}$. The patch withstood the pull of the anchoring mattress sutures after their closure to obtain the scleral indentation over the retinal tear area. After the evacuation of subretinal fluid, an encircling band was inserted.

A satisfactory buckling resulted immediately at the end of the operation with the retina attached. The high buckling of the first week decreased from 8 to 5 dioptres after three months. There was an inflammatory reaction of the conjunctiva overlying the treated area which disappeared after three weeks. The anterior chamber revealed slight flares and a few cells were observed in the vitreous during the first io days after surgery. The retina overlying the area where the scleral patch was glued with histoacryl-blue showed practically no reaction. The intraocular pressure remained normal during the six-month follow-up period.

CASE 2

A 55-year-old woman was admitted with a total retinal detachment with a large tear at the 2 o'clock meridian in her right myopic eye. During dissection of the lamellar scleral trapdoor in preparation for a circling buckling procedure, the scleral bed was so thin that the choroid appeared almost clear (Fig. 2). A very superficial diathermic coagulation was performed. After drying the staphylomatous surface, the dangerously thin sclera was covered with a preserved human scleral patch which was glued with histoacryl-blue and pressed with a finger for one minute. A silicone implant was then placed in the reinforced bed of the trapdoor and a circling element was closed after subretinal fluid evacuation. No extrusion or intrusion of the implant was observed postoperatively, nor was there any inflammatory reaction in the anterior segment or in the vitreous. The retina was attached and the buckling remained unchanged. This case was under observation for more than eight months after surgery.

CASE 3

A 63-year-old man was in hospital for a localized retinal detachment around a large retinal tear at 3 o'clock meridian on the right eye, which was 5 dioptres myopic. The vitreous was attached only in the area of the tear's operculum. It seemed to us that this was a case suitable for a full thickness scleral buckling procedure with silicone sponge explant, but after the detachment of internal rectus we discovered a large staphylomatous scleral area under the muscle corresponding with the retinal tear (Fig. 3). Very superficial diathermy applications were performed. The thin sclera was covered with preserved scleral pocket $3 \mathrm{~mm}$ wider and longer than the damaged sclera, of which three of the four borders were glued with histoacryl-blue. The pocket
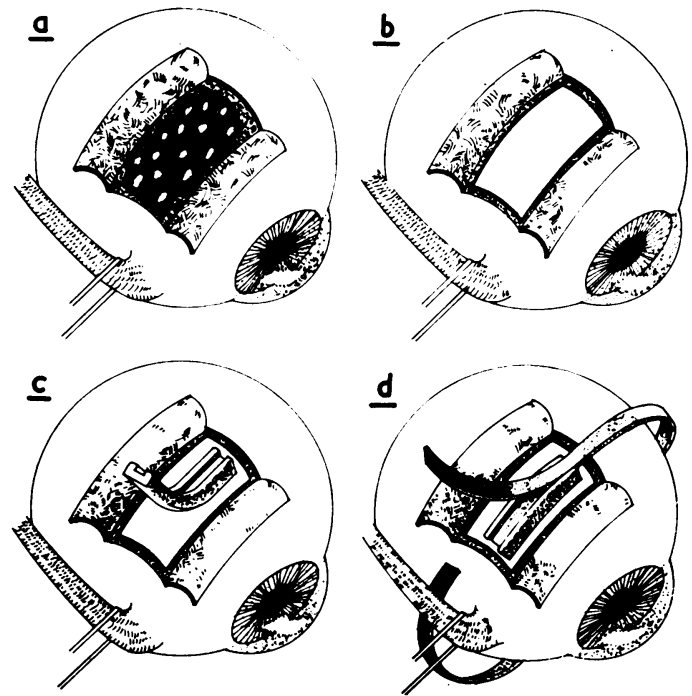

FIG. 2 (a) A few superficial diathermocoagulations were carried out on the necrotic bed of scleral trapdoor.

(b) Defect was covered with preserved scleral patch glued with histoacryl. (c) Grooved silicon implant was placed above preserved scleral patch. (d) Encircling band was inserted 

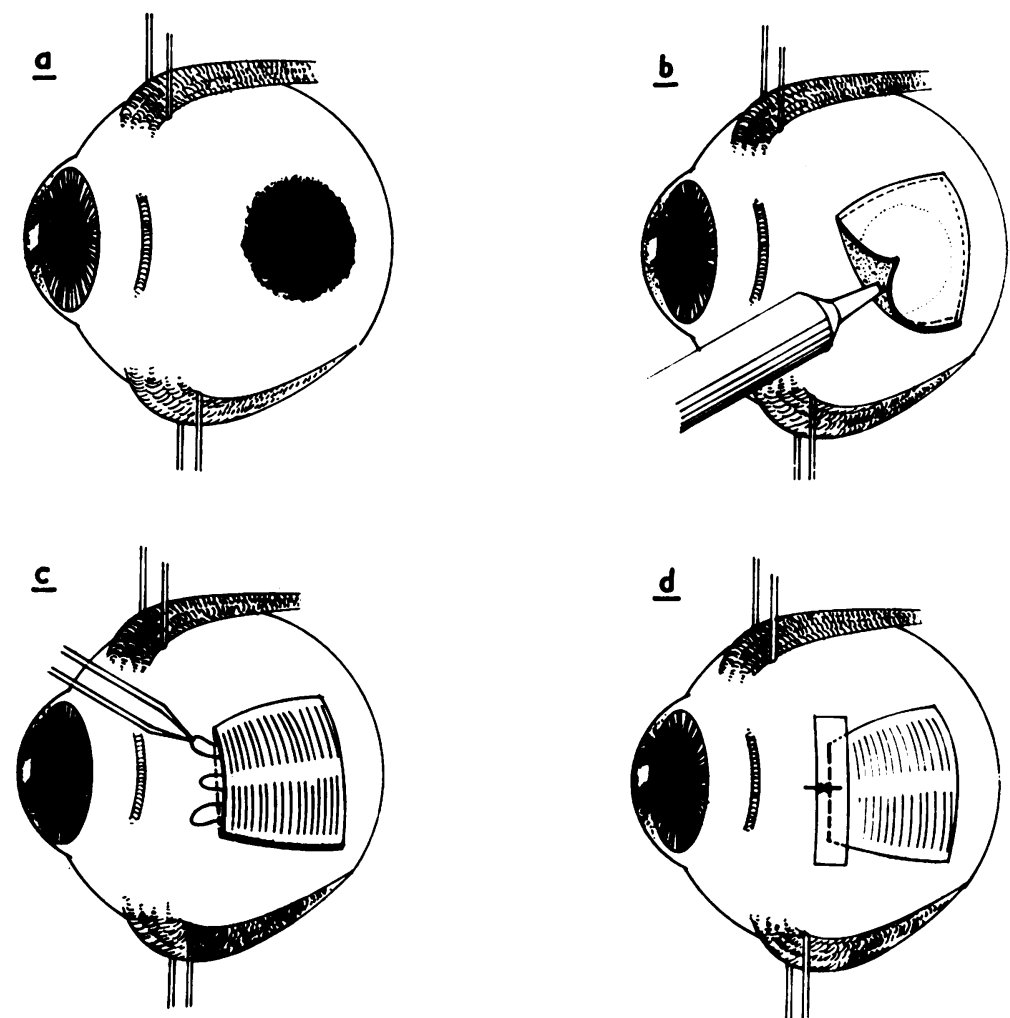

was filled with scleral chips, and its free border was then sutured to the globe with a single mattress suture to obtain more scleral indentation. The open mouth of the pocket was closed with a long strip of preserved sclera glued with histoacryl tissue adhesive. The subretinal fluid was not drained. The internal rectus muscle was reattached to its insertion and the conjuctiva was sutured. After 24 hours the subretinal fluid absorbed spontaneously and the retinal tear was closed. A 5 dioptre high buckling effect was obtained and remained unchanged for six months. As usual there was a slight postoperative inflammatory reaction which disappeared during the first week.

\section{CASE 4}

A 59-year-old man was hospitalized for a recent retinal detachment in his right myopic eye. A horseshoe tear found at $\mathrm{I}$ o'clock was surrounded by a localized small raised retinal detachment.

After the conjunctiva had been opened the scleral appearance was normal and a few full-thickness diathermic coagulations were applied to the area of the tear under ophthalmoscopic control.

The borders of a preserved scleral pocket were glued with histoacryl as in case 3 . The pocket was filled with scleral chips until an appropriate buckle was obtained without any subretinal fluid drainage. The operation lasted 20 minutes.
The subretinal fluid which disappeared after 24 hours showed a small raised buckle of 4 dioptres. A mild conjuctival reaction was observed during the next two weeks, but it disappeared after a topical application of corticosteroids.

\section{Discussion}

Cyanoacrylate has been used in various experimental surgical techniques on the posterior pole of the eye. Studies in cats (Long and others, 1970) and in rabbits (Calabria and others, 1970; Vygantas and Kanter, 1974) have verified the safety and effectiveness of the adhesive tissue in retinal surgery. Although it has been shown that in histological studies (Calabria and others, 1971) cyanoacrylate acts as a barrier to cellular invasion provided that the glue is applied only to the edge of the scleral graft approximation of the scleral host and donor.

It seems to us that the most important indication for the use of histoacryl-blue and preserved sclera is to cover the staphylomatous areas of sclera in highly myopic eyes (cases I and 3 ) and the necrotic areas resulting from too strong scleral diathermy or too deep lamellar scleral dissection (case 2). This method is also recommended in cases in which 
anchoring sutures are necessary for explant in a region of thin sclera where there is danger of perforation. The glueing of a preserved scleral patch with histoacryl-blue to the thin scleral area makes it possible to create a sufficiently thick and safe layer of tissue for suture insertion.

The strength and proper adhesion obtained with histoacryl-blue was positively demonstrated in case I in whom sutures were inserted into the preserved scleral patch, despite our fears of displacing the host sclera when the sutures of the two explant elements were tightened. It is important to make sure that the glued scleral patch is sufficiently large to withstand the pulling of the sutures so that they do not reach the edges of the transplant.

The stability and strength of the histoacryl-blue was also confirmed in cases 3 and 4 in whom the scleral pocket was able to create sufficient buckling.

It is important to maintain a dry field immediately before the adhesive is applied to prevent the glue from polymerizing on the surface as this would result in lack of contact with the sclera. Since the polymerization time is very short, care must be exercised to adapt the tissues quickly and exactly, as mistakes cannot be corrected later. The blue colour of the histoacryl makes it possible to keep the application of the adhesive material at a minimum.

Histoacryl-blue proved to be suitable in these cases as no inflammatory or toxic postoperative reactions were observed. Cyanoacrylates have been tested extensively for carcinogenesis by Kort ( 197 I) and have so far proved to be non-carcinogenic. It seems to us that the histoacryl-blue tissue adhesive can be of value because it combines strength with low toxicity and colour. The use of preserved human sclera glued with histoacryl-blue is being further investigated clinically, but only a long-term follow-up on our patients will confirm its advantages in retinal detachment surgery.

\section{Summary}

Preserved human scleral graft and histoacryl-blue tissue adhesive were used in four cases of retinal detachment surgery to obtain scleral buckling effect and to protect staphylomatous or necrotic scleral areas. The use of histoacryl produced a strong and resistant adhesion between the host and the preserved scleral patch. The postoperative inflammatory reaction was mild and disappeared within one week.

\section{References}

Calabria, G. A., Pruett, R. C., and refojo, M. F. (1971) Arch. Ophthal., 86, 82

$\longrightarrow, \longrightarrow, \longrightarrow$, and SCHEPENS, CH. (1970) Ibid., 83, 61 3

ELlis, R. A., and Levine, A. M. (1963) Amer. $\mathcal{Y}$. Ophthal., 55, 733

HEALEY, J. D. (1965) Amer. F. Surg., ro9, 416

KORT, J. (197I) 'Klebstoffe in der Chirurgie', ed. Schattauer, Struttgart

LONG, R. S., MitTli, R., and ChUANico, R. (1970) Amer. Y. Ophthal., 69, 4 I9

Natan, H. S. (1960) Ann. Surg., 152, 648

PAufiQue, L., and hervouet, f. (1962) Ann. Oculist. (Paris), 195, 385

PRUETT, R. C. (1972) 'Retina Congress', p. 523. Appleton-Century-Crofts, New York

SEELENFREUND, M. H., REFOJO, M. E., and SChEPENS, CH. (1970) Arch. Ophthal., 83, 619

Straatsma, B. R., Allen, R. A., hale, P. N., and gomez, R. (1963) Trans. Amer. Acad. Ophthal. Otolaryng., 67, 320

vygantas, M. C., and Kanter, P. J. (1974) Arch. Ophthal., 91, 26 